\title{
Big Data Approach to Visualising, Analysing and Modelling Company Culture: A New Paradigm and Tool for Exploring Toxic Cultures and the Way We Work
}

\author{
${ }^{1}$ Kristin O’Brien, ${ }^{2}$ Suresh Sood, ${ }^{3}$ Rohan Shete \\ ${ }^{1,3}$ Voop.Global, Melbourne, Australia \\ ${ }^{2}$ University of Technology, Sydney, Australia
}

\begin{abstract}
This paper explores the use of big data to measure company culture, good and bad, including toxic culture. Culture is a central factor driving employee experiences and contributing to the "great resignation". Harnessing the key Artificial Intelligence (AI) technology of neural networks using deep learning methodology for NLP provides the capability to extract cultural meanings from a diverse array of organizational information and cultural artefacts ( texts, images, speech and video) available online. Using big data and AI provides a predictive capability surpassing the value of employee survey instruments of the last century providing a rear view of insights. Big data helps break free from the paradigm of only thinking about culture moving at a glacial pace. An innovative methodology and AI technologies help measure and visually plot the organizational culture trajectory within a company cultural landscape. Cultural values, inclusive of toxicity, have the potential for detection across all forms of communications media. A non-invasive approach using a broad range of open data sources overcomes limitations of the traditional survey instruments and approaches for achieving a culture read. The benefits of the approach and the AI technology are the real-time ingestion of ongoing executive and managerial feedback while entirely sidestepping the issues of survey biases and viable samples. The methodology under study for reading a culture moves well beyond traditional text-centric searches, content analyses, dictionaries and text mining, delivering an understanding of the meanings of words, phrases, sentences or even concepts comprising company culture. Embeddings are an ideal neural network breakthrough technology enabling the computation of text as data through creating a meaningful space in which similar word meanings exist in close proximity. Vector algebra in a multidimensional space helps unpack the cultural nuances and biases pent up within the unstructured information flowing through and from organizations, from tweets to text-centric corporate communications, including annual reports. This modelling enables predictions about an organizational future culture based on communication data existing across internal and external digital platforms. The variety of communications represents the twenty-first century culture requiring exploration and discovery. Visualizations of the traces of multiple dimensional cultures make current-state and culture predictions for an organization and competitive organizations in the same or adjacent industries within a company cultural landscape.
\end{abstract}

Keywords: Culture, Natural Language Processing, Artificial Intelligence, Open Data, Annual Reports, Big Data

\section{Introduction}

This paper describes a methodology and tool for culture observation, tracking, predicting and measurement without recourse to survey instruments. Although organisational culture is a focal point of this paper, the elements and coverage of the innovative method and technology have far-reaching influences well beyond culture, including (but not limited to) employee experiences. The concept of customer experience and segmentation although originating within marketing, the idea extends to employees (Venaik and Midgley, 2015). Historically, 
the construct of work relied upon employees adapting to managers, and managers adapting to organisations (Morgan, 2014). However, as we move towards a future where a shortage of labour skills exist and where we understand the benefits of an engaged workforce means organisations are needing to adapt to employees not the other way around. In 2015, Ninety percent of recruiters were already recognising that the power has shifted to the candidate and that employees had become 'volunteers' (Bersin, 2016).

Today, employees expectations of work experiences more closely align to the experience of personalisation, viewing and shopping at an Amazon, Netflix or Starbucks. This experience is the consumerisation of HR and "describes the idea of creating a social, mobile, and consumer-style employee experience" (Wickham, 2017). Engagement is a combination of small drivers rather than one big driver engaging employees. Little drivers could be performing work with a social impact, working flexibly, surfing or swimming at lunchtime, opportunities to work in different parts of the organisation, learning new skills or receiving recognition. The key for leaders is to be able to discover the patterns of experiences engaging their employees to provide the optimal employee experience beyond just a job "home away from home"(ibid).

\section{Essential Elements of Employee Experience}

According to the employee experience "manifesto for the future of work" (Kazoo 2020) four pillars comprise employee experience. Feeling a connection, growth, social impact, and appreciation (ibid) helps to motivate employees and create a sense of engagement with the organisation. A holistic employee experience framework encapsulates the direct relationship between a healthy, vibrant company culture and employee experience.

\subsection{Connection}

As companies look to become more and more high technology focused, what seems to set them apart, is a degree of humanness (Mohr, Ghazianni, 2014). Connection between humans is a superpower resulting in productivity, happier and healthier environments (Smith, 2013). Neuroscience provides evidence when people feel lonely or socially isolated the select parts of the brain that light up are the same as those triggering physical pain. On the flip side of this, when we feel positively connected to another, and feel a caring emotion towards others, our pleasure centres light up. At work, these feelings of pleasure come from feeling valued, aligning with what your company stands for, being recognised for your contributions or simply having meaningful relationships with the people in your neighbourhood (Lloyd, 2018). Rasca describes connectedness as one of the most important levers of organisations in driving retention (2018).

\subsection{Engagement}

If an employee shifts from just satisfied to engaged this is an uplift of $45 \%$ increase in productivity (Galton and Mankins, 2020). Engagement is also closely linked to connectedness. Employee engagement can be described as how employees are feeling at a point in time and the degree to which employees feel connected to their employer (Eaglebarger, 2017). Company culture, the freedom to work and perform, exceptional leaders and inspiring managers form key elements of an engaged workforce (Rasca, 2018).

\subsection{Impactful Work}

Impactful work can be described as knowing the work I do impacts my colleagues, my company and my community for the better (Youearnedit, 2018) (Smith, 2013). Impactful work also relates to our connectedness. When we feel like we are doing work that has impact, this allows us to feel connected to a higher purpose (Lloyd, 2018). Work that has impact creates meaning for employees (Lysova et al, 2019). Clausen and Borg describe impactful work as associated with improved mental and physical health, as well as driving employee engagement (2011).

\subsection{Ease of Interaction}

Organization 'You earned it' surveyed more than 750 employees at over 600 companies (Kazoo, 2020), and discovered that when asked what factor influences their employee experience the most, $49 \%$ of employees chose culture. Interestingly, the other 51\% was made up of technology and tools and the physical environment they operate in. It's these technology and tools and the physical environment which influence the ease of interaction and relate closely to the consumerisation of the employee experience. Employees want to be able to order equipment to do their job, as easily as they would order groceries online. Cumbersome processes that include 
forms in triplicate seem archaic, when considered through a consumer lens, and do not make an exemplary employee experience.

\subsection{Well-being}

A clear link exists between organisational culture and employee well-being. Connectedness is one element, influencing the human brain's pleasure response when employees feel connected to each other, their leaders or the organisation as a whole. There is also a clear link between employee well-being and a toxic company culture. Organisations, as well as employees can suffer from the effects of toxins that are present with an organisation (Appelbaum \& Roy-Girard 2007). These toxins are not the ones kept in the chemical storeroom, rather they are the negative elements of organisation life that employees experience on a daily basis. The effects of this on wellbeing can be impaired judgement, irritability, anxiety, anger, an inability to concentrate, and memory loss.

\section{Culture}

Although the concept of organisational culture has been around since the 1970s, only more recently have management consultants and senior-level executives built on culture as an explanation accounting for the difference in performance between two like organisations (Glynn, Giorgi, Lockwood, 2018). Furthermore, culture significantly impacts organisational outcomes and provides a potential source of competitive advantage (Gupta 2011). For this reason, the measurement and management of organisational culture is a valuable lever for the leadership team and consultant toolkits.

Organisational Culture represents the values and norms that characterise the structure in place to guide employee actions when facing unforeseen contingencies (Graham, Grennan, Harvey, 2017). Core values (Gupta, 2011) or cultural values (Venaik, Midgley 2015) represent the principles and ideals determining the state of the behaviour of a community. Cultural norms (Cooke, Rousseau 1988) are the day-to-day living out of the cultural values (Leung, Morris 2015).

The core values of an organisation, together with the mission, guide employees through the execution of an organisation's strategy (Andrus 2019). The combination of core values and mission define the espousing organisational culture. However, often, the reality is different (Detert, Schroeder, Mauriel, 2000). To truly understand an organisation's culture, one must measure the degree to which the desired culture is observable in the everyday living out of what it espouses to value.

Most importantly, through dynamic measurement and proactive management of organisational culture, leaders have an opportunity to minimise toxicity as well as those elements of culture not serving the strategy (Caprar et al., 2015). When organisations continue to perform as they have always done, due to a reluctance to change, the impact on performance and results can be severe.

\section{Toxic Culture}

The elements of a toxic culture are difficult to articulate, but employees experiencing such a culture know how it feels. Words synonymous with toxic are fear, blame, shame and confusion. These words are useful when describing an unhealthy organisation.Toxic cultures are mostly ineffective as well as destructive to employees (Appelbaum \& Roy- Girard, 2007). A 2017 survey finds 85\% of employees believe a poorly implemented, weak culture increases the chance that an employee might act unethically or even illegally (Graham et al., 2017). A toxic culture can lead to an increase in bullying cases, which in turn leads to an increase in sick leave and employee turnover. Incivility between employees also increases, leading to incivility towards customers and higher customer churn. These impacts are estimated to decrease an organisations overall productivity by up to $40 \%$ (Bremer, 2019). A picture paints a thousand words and vignettes (Grønhøj \& Bech-Larsen, 2010; Wason, Polonsky, \& Hyman, 2002; Sood \& Pattinson 2013; Woodside \& Sood 2016) represent an ideal technique and approach for the investigation of culture and toxicity. A diverse compilation of six contemporary vignettes helps explore toxicity in organisational cultures.

\subsection{Theranos Vignette}

In 2014, the Theranos' value equates to USD 9 billion, building on the idea of a blood test requiring only a tiny droplet of blood from a fingertip. Theranos runs a command and control organisation with Elizabeth Holmes, the $\mathrm{CEO}$ and Founder at the centre. Holmes' extraordinarily charismatic character, now proven deceitful, drives a 
culture of secrecy, lies and poor treatment of employees (Carreyrou, 2018). Consistent with her leadership style, Holmes always tells small lies about false accomplishments to appear more intelligent (Bilton, 2019). Additionally, her big lies about the capability of the product, help raise a total of $\$ 900$ million from investors. It is only a matter of time before others discover Theranos does not have the ability or capacity to build the product or live up to its promises to the public and investors. The culture of secrecy and deceit leads to abysmal communication throughout the organisation. Stakeholders have no real idea of what is going on within the company. Internally, Theranos' culture leads to distrust between departments. The lack of sharing of information results in poor decision-making and re-work. Theranos sets an ambitious stretch goal strongly emphasising a shared and unified vision; however, employees feel they are unable to question or challenge the business direction (Ying, 2019). Elizabeth Holmes faces potential time in prison for fraud but some may argue this is part of a "selling the dream" culture.

\subsection{Cricket Australia Vignette}

In March 2018, a ball-tampering scandal in South Africa engulfed the Australian men's cricket team. Television cameras catch one of the player's ball tampering. He is clearly shown trying to rough up one side of the ball with sandpaper to make it swing in flight. Mickey Arthur, a former team coach of the team, makes the following observation:'So here we are. A cultural issue that should've been addressed a long time ago wasn't. It has all gone bang' (Webber, 2018). After the ball-tampering incident, the Captain, Deputy and Opening batsman face bans from playing International cricket for long periods. Much discussion ensues about whether or not those banned are victims of a toxic culture rather than wholly accountable for their actions (Gideon, 2018).

Because of the speculation about the state of cricket in Australia, the Board of Cricket Australia commissions a report investigating the culture of the organisation and seeks corrective recommendations. $\mathrm{ABC}$ news reports on the findings and describes them as 'scathing' (ABC News NSW (ABC1 Sydney), 29 October 2018). The Ethics Centre report damns the culture at Cricket Australia where player considerations are not as a talent but indeed as commodities; they exhibit poor behaviour, are arrogant, sledging is commonplace, and they even abuse their staff (2018).The toxic culture at Cricket Australia is exposed on television around the world, through the actions of one player. This example shows the flow-on effect of a toxic culture and how it can incite behaviour a reasonable person would deem unacceptable.

\subsection{CBS Vignette}

CBS Corporation is an international media organisation, headquartered in North America. They are creators and distributors of media content with operations spanning every field of media entertainment. In July of 2018, a report prepared for the CBS Board investigating a culture where bullying, verbal abuse and sexual harassment thrive (Haring, 2018), is leaked to the public. Six women come forward describing disturbing encounters and physical threats made towards them by CEO Leslie Moonves (Farrow, 2018). Stories of misconduct dating back to the 1990s are exposed, with the \#metoo movement encouraging many who have kept quiet for years, to come forward (Hillstrom, 2019). Bradley, in her article titled 'Former CBS Executive slams the Network for the "white problem"' refers to an essay by Whitney Davis where discrimination, gender bias, and inappropriate behaviour is pretty much commonplace at CBS (2019).

\subsection{Australian Royal Commission Vignette}

The Australian Royal Commission into Misconduct in the Banking, Superannuation and Financial Services Industry reveals a culture of toxicity within the sector. When the interim report was released, the presiding commissioner comments:

"...a frank and scathing assessment of the culture, conduct and compliance of our financial system. Australians expect and deserve better." (Murphy, 2018)

An internet search of Australia's financial institutions shows that Australian Banks all subscribe to values of Integrity, Service, Collaboration, Excellence or similar. Yet what we see in the case of financial institutions that appeared at the Royal Commission is significant misalignment between the values championed and the general workforce attitudes and conduct. The royal commission hears cases of customer fees for services never received as well as instances of people being charged fees even after they are dead (Chalmers, Worthington, 2019). Aggressive sales techniques, such as cold calling, are used with an individual living with a learning disability. Instances of vulnerable customers being sold Insurance without understanding what they are buying as well as 
insurers making it impossible for customers to make claims on their policies (Commonwealth of Australia, 2019) surface at the inquiry. Considering what Australian banking organisations publicly state as their values, there is a significant gap between the indicated point and reality. Integrity, service, collaboration, and excellence are not driving their 'employees actions when they face unforeseen contingencies' these values are not evident even with clear guidelines for staff to follow.

\subsection{Traeger Vignette}

Traeger Pellet Grills is founded in 1987. In 2013 the company emerges as a small, local business with $\$ 70$ million in sales. In 2018, because of a new CEO and a change to the company culture, it is now a global business achieving nearly $\$ 400$ million-plus in sales (Andrus, 2019). In the US, the grilling market is worth about $\$ 5$ billion, including grills, fuel and accessories (Feldman, 2017). CEO, Jeremy Andrus, tells the story of how he transformed the Culture of Traeger in the Harvard Business Review (Andrus, 2019). He describes the indicators alerting him to the toxicity of the culture. When asking the team for data, they ignore him. When the CEO asks to meet with the CFO is that he doesn't have time. Requests for people to work together on projects are ignored. The majority owner undermines the CEOs authority by regularly speaking to the team. Furthermore, the employees are fearful of the majority owner who drives an aggressive and abusive style that permeates through the organisation. The other element he sees is a lack of data-driven decision making. In the early days, it takes the CEO a week to receive the information he requests (CEO.com, 2019). This slowness of information creates a lack of transparency and objective decision making.

\subsection{France Telecom Vignette}

In December of 2019, three former executives of French telecommunications company Orange (formerly known as France Telecom) are found guilty of creating a corporate culture so toxic that 35 of their employees are driven to suicide (Thebault, 2019). The organisation is not performing and is under pressure to transform from an economic model based upon industrial production, to a model of financial capitalism (Waters, 2014). The organisation has a headcount reduction quota that with no industrial instrument for redundancy, and no open job market for resignation, seems impossible to meet. The tight industrial relation controls mean that layoffs were near impossible, and due to a national landscape of 'jobs for life', resigning from one organisation to move to a job in another organisation is highly irregular. In response to this, the CEO, Didier Lombard, was on record in 2017 as saying that he would reach the quota of layoffs "one way or another, by the window or by the door." (Nossiter, 2019). Management uses "pathogenic" restructuring methods, such as forcing people into new jobs in far-away cities and giving them unattainable performance objectives (ABC.net.au 21 December 2019). This is enabled by a toxic culture of underemployment, marginalization, miscasting and systematic harassment (Nossiter, 2019). Individuals are put into roles vastly different to the role they are hired for, with no capability or desire to do their new job and no training to assist with the transition. Through this strategy the organisation manages to create widespread disorientation, destroy employees' sense of self-worth and professional identity. The forced relocation of staff away from family and friends is untenable. With no opportunity to find employment elsewhere, employees feel hamstrung and unable to make choices. The suicides are not a tragic accident or an aberration of management practices, rather a deliberate and systematic campaign carried out by managers to force workers to leave the company (Waters, 2014).

\subsection{Patterns of Toxicity}

The common characteristics emerging from the vignettes exhibiting a toxic culture are:

1. Inability to achieve operational goals and commitments

2. Unchallenged, poor-quality decision-making resulting in lots of re-work and waste

3. Poor internal communication

4. Diffusion of responsibility

5. Fear of authority resulting in interpersonal relationships driven by manipulative and self- centered behaviour

6. Leaders not held accountable for actions (Gottshalk, n.d.; Appelbaum \& Roy-Girard 2007)

7. Employees do not feel safe, respected and do not have a voice 
8. Impacts on employee health and well-being

9. Employees unable to operate at full potential

10. Lack of data for evidence base decision making

\section{Big Data Approach to Measuring Culture and Toxicity}

High growth and high performing savvy companies describe in detail the culture they desire to enable the execution of strategy. Examples of these organisations are Hubspot (Shah,2018); Atlassian (Garfield, 2015) and Slack (The Slack Team, 2015). These high performers measure how the reality reflects their desirable culture and experience, focusing on cultural consistency and the measurement and observation of the alignment between the desirable and current state values. Such companies treat cultural measurement as an ongoing process (Elzinga, 2018).

Today, the two most common methods of measuring culture are:

1.) Values-based survey providing results generating discussion with caring leaders driving change.

2.) Cultural diagnostic using a combination of interviews focus groups and surveys. An excellent cultural diagnostic methodology helps enable the organisational review of Cricket Australia (Ethics Centre 2018). A cultural diagnostic yields a culture assessment with a high level of detail and actionable recommendations. However, the cultural diagnostic provides actions after the event and not forward looking providing lessons for others.

Both methodologies rely on gathering information based on intentionality, with informants saying what they will do or have done. Here, the researcher method contrasts markedly with observing in a non-invasive fashion, what people do within natural settings, including the workplace.

Very importantly, a third alternative is the use of big data for representing and interpreting culture. Using big data helps avoid the halo and Hawthorne effect (Graham et al., 2017). Surveys with complementary observations of people's actions, behaviours and reactions minimise people's self-delusion (Tang, 2017). Using big data emanating from employees, customers and the public interactions, organisations have the potential for a culture read without recourse to a survey instrument. A simple measurement system is no longer sufficient to understand the complexities of 21st century high-speed culture. This notion of high-speed culture is an oxymoron given culture traditionally associates with change at a very slow pace. But what makes culture different today is big data (vast volumes of unstructured data or non-financial information including text, video, images and audio) flowing through and from organisations across numerous touch-points.

A real understanding of organisational culture requires observing people using culture in real- time as an unfolding pattern of deliberate choice and action (Mohr, Ghazianni, 2014). The stories people share help make sense of organisational life. Finding these stories in real-time arise from communication data. Constructing and interpreting syllogisms from different stories ensures descriptions are less likely to be misinterpreted and provides a deeper understanding of the organisation culture (Feldman, Sko ldberg, Brown and Horner 2004).

Whether the organisation is talking about itself, or others are talking about the organisation, people's word choice represents a window to an organisation's culture (Srivastava, 2017). Because of the dynamic nature of communication data, changes in culture over time are observable and measurable. Linguistics highlight what people say, think and do as well as tell us what people value, and the norms of what they adhere towards.

Using big data has advantages over the use of typical survey instruments and represents an observation of the entire cultural landscape. The real-time aspect provides results whenever new communication data is available. Because of real-time capability, alerts can signal culture moving towards a higher level of risk or at least facilitate thinking about a predictive trajectory even before movement towards a weaker culture.

\subsection{Culture Measurement Methodology}

The methodology for measuring culture converges a big data and values approach. Culture comprises patterns of values and behaviours across multiple dimensions rather than as individual traits (Venaik, Midgley 2015). For 
this reason, big data is a source of insight into these culture patterns. Evidence of values as well as the norms associated with them is found in all the types of communication data, video, images and emoticons.

\subsection{Measuring Organizational Culture using Values}

The researchers test the approach using the values dictionary to scan a series of publicly available documents either written for or relating to, a test company (see table 1). The alignment with the company values is measurable from communications and a cultural assessment generates. A results verification stage and conversation with senior leaders from each of the test organisations conclude the usefulness and selection of measuring values.

Table 1: Company A to D Extraction of Company Values from Communications Media

\begin{tabular}{|l|l|l|l|}
\hline $\begin{array}{l}\text { Company A: } \\
\text { insurance }\end{array}$ & $\begin{array}{l}\text { Company B: } \\
\text { telecommunications }\end{array}$ & $\begin{array}{l}\text { Company C: commercial } \\
\text { real estate }\end{array}$ & Company D: banking \\
\hline $\begin{array}{l}\text { Although the } \\
\text { organisation is talking } \\
\text { a lot about values } \\
\text { customers and } \\
\text { external stakeholders } \\
\begin{array}{l}\text { are not hearing the } \\
\text { internal messages. }\end{array}\end{array}$ & $\begin{array}{l}\text { People are focussed } \\
\text { too much on what they } \\
\text { do not how they do it. }\end{array}$ & $\begin{array}{l}\text { Employees are clearly } \\
\text { identifying with three of } \\
\text { their own values. } \\
\text { However, one of the } \\
\text { values is not evident } \\
\text { internally or external to } \\
\text { the organisation. }\end{array}$ & $\begin{array}{l}\text { Although the } \\
\text { organisation is talking a } \\
\text { lot about values } \\
\text { customers and external } \\
\text { stakeholders are } \\
\text { hearing obfuscated } \\
\text { messaging. }\end{array}$ \\
\hline
\end{tabular}

All four companies receive a report using the big data culture prototype to validate the accuracy and usefulness of both tool and method for reading cuture. In each of the companies A to D, the senior executives and managers consulted confirm the researcher findings matching the organisational internal assessment of the current state of company culture.

Beyond the initial experimentation, the researchers commence with a list of frequently appearing core values (Vantrappen and de Jong, 2018) amongst the top 100 Fortune organisations on their websites and categorise core values into groups of similar values for 450 organisations. This analysis results in the categorisation of 2500 words representing different values inclusive of similar words, phrases and sentences. A common list of shared values is generated using the Wordnet software from Princeton University to group meaningfully related words and concepts. The final list of values comprises twenty terms and compares favourably with the initial list (ibid). Table 2 shows the final output from the categorisation activity.

Table 2: Cultural Values Frequently Listed from Company Annual Reports
1. Accountability*
11. Leadership
2. Communication
12. Learning
3. Community
13. One -Team *
4. Courage
14. Partnership *
5. Customer-First *
15. Passion
6. Entrepreneurship
16. People *
7. Excellence *
17. Playfulness
8. Humility
18. Productivity
9. Innovation *
19. Professionalism
10. Integrity *
20. Respect 
Of the 20 Values frequently listed, Table 3 uses inputs from the panel of researchers regarding whether or not the opportunity exists to measure the values using publicly available data. The exploration of publicly available data for measuring culture is encouraged 'although a rich collection of research has examined stories as culture through a focus on company archives and print, future research might explore company websites, webcasts, online photo galleries, or oral histories to deepen understanding of culture as stories in organizations' (Glynn, Giorgi \& Lockwood 2015). Examples of data sources consulted include a firm's appearance in the top 100 Great Places to Work; and analysis of corporate financial reports, conference calls and websites (Graham, Campbell, Jillian, and Shivaram 2017).

Table 3: Open Source Opportunities to Measure Culture Values

\begin{tabular}{|c|c|c|}
\hline ID & Value & Comment with regard to measure from open or public data \\
\hline 1 & Accountability & $\begin{array}{l}\text { Although whether employees are accountable to each other would not be shown, } \\
\text { accountability to customers and to the community }\end{array}$ \\
\hline 2 & Communication & $\begin{array}{l}\text { Evident through the breadth,depth and quality of communication residing on } \\
\text { public and private digital platforms. }\end{array}$ \\
\hline 3 & Community & $\begin{array}{l}\text { The response of the community to an organisation will show the degree to which } \\
\text { employees value the community. }\end{array}$ \\
\hline 4 & Courage & $\begin{array}{l}\text { A culture that values courage demonstrates this via a willingess to take action, } \\
\text { advocacy, not being intimidated by failure, challenging the status quo. Traces of } \\
\text { this occur throughout communication. }\end{array}$ \\
\hline 5 & Customer First & $\begin{array}{l}\text { An organisation's orientation towards the customer perspective can be measured } \\
\text { by public opinion. Other indicators are brand consistency, customer retention, } \\
\text { responsiveness to customers and language used to talk about their customers. }\end{array}$ \\
\hline 6 & Entrepreneurship & $\begin{array}{l}\text { Observations of the degree to which entrepreneurial behaviours are encouraged, } \\
\text { accepted or tolerated within an organisation. This could be reflected in how } \\
\text { opportunistic the organisation is, profit growth, tolerance of risk, empowerment } \\
\text { of employees. }\end{array}$ \\
\hline 7 & Excellence & $\begin{array}{l}\text { Shown through external awards and other kinds of recognition from external } \\
\text { stakeholders, a focus on quality, language that focuses on winning, being the } \\
\text { best, achievement. }\end{array}$ \\
\hline 8 & Humility & $\begin{array}{l}\text { Evident in the organisational tone of voice and may be observed through } \\
\text { comments by external stakeholders. }\end{array}$ \\
\hline 9 & Innovation & $\begin{array}{l}\text { Observable as new products launch through product reviews, customer feedback, } \\
\text { risk taking, flexibility, diversity, agility and consideration of transformation } \\
\text { activities in the organisation. }\end{array}$ \\
\hline 10 & Integrity & $\begin{array}{l}\text { 3rd party data sources including glassdoor.com and even Wikipedia are } \\
\text { indicative. Also observable through customer mentions of organisations as honest } \\
\text { and 'doing the right thing' (or opposite). Examples of congruence/incongruence } \\
\text { sited by stakeholders. }\end{array}$ \\
\hline 11 & Leadership & $\begin{array}{l}\text { For larger organisations only, where Senior Leaders have public profile. } \\
\text { Although there may be exceptions, the Leadership style of Senior Leaders would } \\
\text { usually cascade through the communications artefacts and data. }\end{array}$ \\
\hline 12 & Learning & $\begin{array}{l}\text { Recognizable through signs of progress, whether they be process improvement, } \\
\text { increased customer satisfaction or others. }\end{array}$ \\
\hline 13 & One Team & $\begin{array}{l}\text { A culture of 'one team' creates a seamless experience for external stakeholders } \\
\text { dealing with the organisation. }\end{array}$ \\
\hline 14 & Partnership & $\begin{array}{l}\text { A culture of partnerships can be demonstrated through examples of the } \\
\text { organisation partnering with others to achieve outcomes. }\end{array}$ \\
\hline 15 & Passion & $\begin{array}{l}\text { The tone of voice used by people recognising the organisation, and by the passion } \\
\text { external stakeholders see in the organisation. Through interactions with the } \\
\text { organisation it is clear what it stands for. }\end{array}$ \\
\hline 16 & People & $\begin{array}{l}\text { This relates to how organisations treat it's people (or workforce). To some degree } \\
\text { this could be measured by 'best place to work' awards or 'diversity and } \\
\text { inclusion' awards, however to get a true sense of the heart of the organisation } \\
\text { holding a mirror up to how an organisations workforce treat external stakeholders } \\
\text { will be valuable. }\end{array}$ \\
\hline 17 & Playfulness & $\begin{array}{l}\text { Playfulness, or the fun people have at work, is usually visible through social } \\
\text { media and company web pages. It can be picked up in images and stories of } \\
\text { events, and in company web pages. Also observable through tone of voice in } \\
\text { company websites and other materials eg job ads. }\end{array}$ \\
\hline
\end{tabular}




\begin{tabular}{|l|l|l|}
\hline 18 & Productivity & $\begin{array}{l}\text { To a degree, performance and results data will infer whether the culture of an } \\
\text { organisation values productivity. Also, observable through customer discussions } \\
\text { about the organisation. }\end{array}$ \\
\hline 19 & Professionalism & $\begin{array}{l}\text { Professionalism is based on the perception of external stakeholders, so for this } \\
\text { value, using public communication data will be of most value. }\end{array}$ \\
\hline 20 & Respect & $\begin{array}{l}\text { To understand the degree to which employees treat each other with respect will } \\
\text { be projected in how employees treat people outside the organisation. There will } \\
\text { also be some overlap with productivity and respect for time. }\end{array}$ \\
\hline
\end{tabular}

The cultural values (table 3) are useful for the foundation of a cultural dashboard (figure 1 illustrates a culture read for the key players in the Australian travel industry) to show the measurement of each of the values on a sliding scale at a point in time, as well as changes overtime.

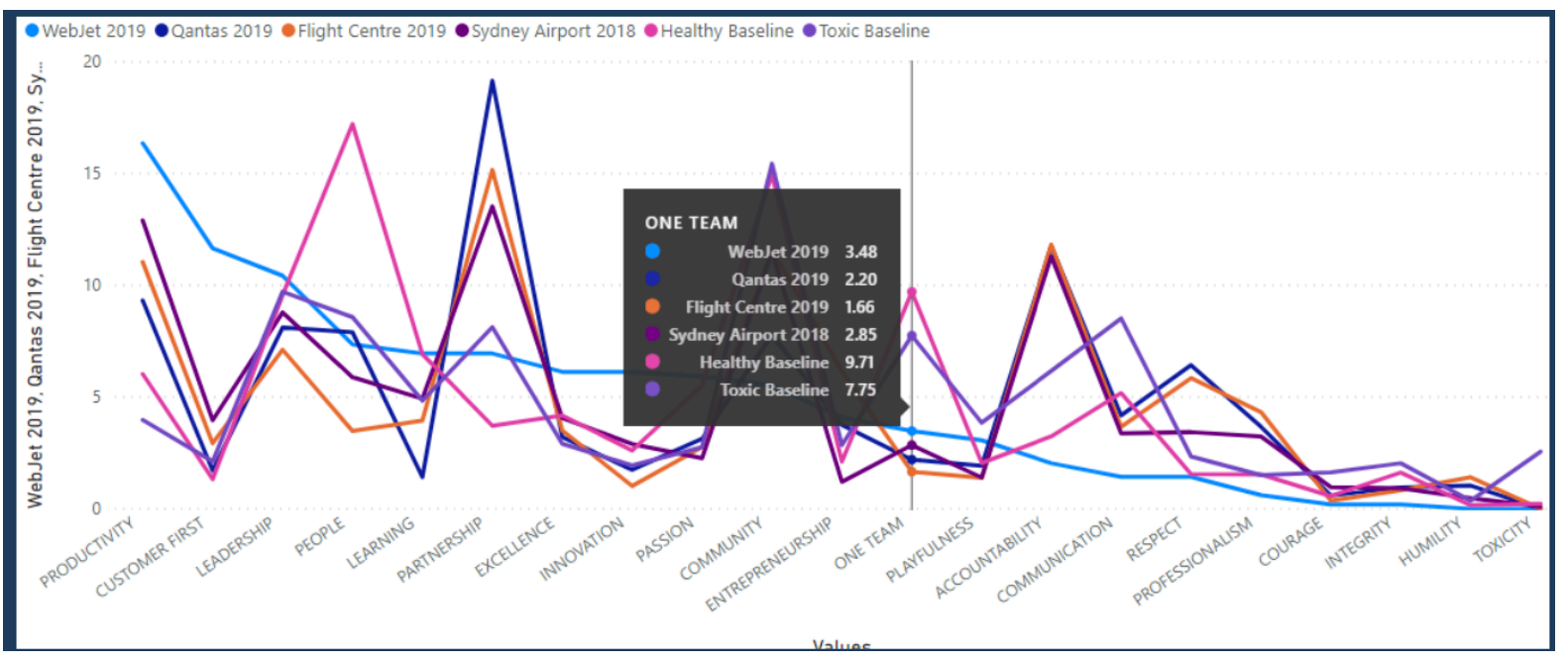

Figure 1: Culture Dashboard of Values for Australian Travel Industry

The culture value categorisation provides a coding system and the foundation for a culture analysis based dictionary. The researchers extract publicly available data from social media, blogs, forums, websites and online news using a social media monitoring tool (Meltwater social monitoring) to obtain thousands of 'mentions'. These mentions are a proxy for answers to survey questions. The mentions are tantamount to survey responses, without asking a question, or even knowing what question to ask. Using humans to recheck the coding generated from social media refines further the meaning behind the mentions. The human annotated manual coding further 'trains' the culture analysis dictionary to automatically code thousands of records. This automated coding exercise helps generate a dictionary that can be used to code and measure culture from unstructured documents or information sources. The results are visualisable in a series of charts and graphs (see figure 2 ANZ Bank by culture values for 2019). Overall, the measures of culture are not absolute but representative of the strength of the value. This measure of value when aggregating with other values helps provide directionality of the culture in multi-dimensional space for a future period

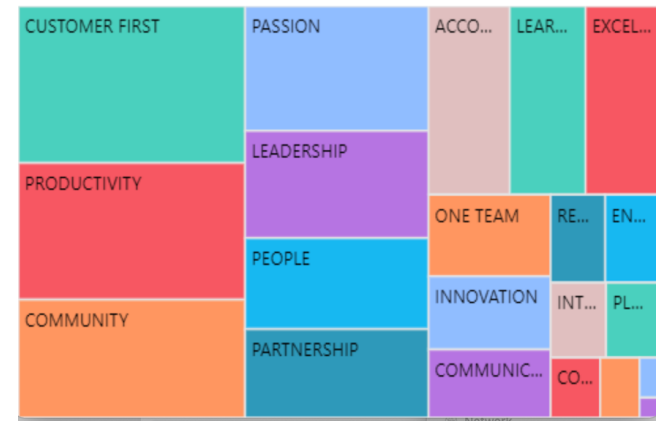

Figure 2: ANZ Bank Culture by Values (2019) 


\subsection{Measuring Organizational Toxicity}

Indicators of toxicity can be found using the Wikipedia talk page edits dataset provided by the Toxic Comment Classification Kaggle competition (Kaggle, 2018). This data set has been tested using AI and deep learning (Ibrahim, Torki and El-Makky, 2018). The authors use the 15,9571 toxic records already labelled by human raters for toxic behaviour. This resulting training data was the starting point for the researchers of this paper measuring toxicity within an organisation.

\section{Deep Learning Natural Language Processing of Culture}

The researchers recognise the necessity to move away from a manually intensive dictionary approach. An unprecedented explosion of unstructured textual data within organisations, company documents online, on company websites, forums, company review websites (e.g. Glassdoor), job advertisements and social media sources inclusive of Twitter and LinkedIn merits an automated approach. The use of a NLP culture analysis tool in reading culture provides managers, consultants and a leadership team a capability to navigate global uncertainties and avoidance or minimisation of a culture of toxicity. Open-source intelligence (OSINT; data acquisition from publicly available sources including company annual reports) helps create measures of cultural values. Namely, the culture change represents the drift away from the values of the organisation under study and the desirable future trajectory relates to the simplest path and actions to bring the organisation back on track to meet core values. Specialised dictionaries (e.g. Linguistic inquiry word count and regressive imagery dictionaries) further help assess the physiological disposition at the time of publishing or broadcasting the communications.

The benefit of deep learning approaches in NLP, over traditional machine learning, is each word has a unique vector associated with it representing the polysemous nature of words in unstructured texts. The AI neural networks learn word representations through unsupervised training over a large corpus. Deep learning describes models that learn to map a set of words or phrases to high dimensional vectors. In the context of culture, word embedding can tell us the proximity of the words to describe an organisation (by customers, employees and other stakeholders) to a healthy culture. Thus, giving us a measure of the degree to which an organisational culture is healthy. We can also measure the degree to which espoused values are demonstrable such as great customer service. This model approach enables predictions about an organisation's future behaviour building upon the unstructured communication data. Every piece of digitised communication data about an organisation or by an organisation contains the traces of culture. By aggregating culture measures for the top $5-10$ organisations in a vertical market an industry benchmark on culture can be established building on open sources.

Over time the culture measures by industry and values using the embedding vector spaces. Once the vector transformation and computation takes place a distance measure (a combination of cosine similarity, cosine distance and Euclidean distance) helps show similarity between documents of similar meanings such as annual reports for companies in a similar industry. Furthermore, the beauty of using OSINT and historical documents helps identify periods of great culture change with timelines within the documents as well as simulate and potentially forecast future trajectories leading to optimum culture. The culture space is known by the researchers as the Company Culture Landscape (CCL).

\section{Company Culture Landscape and Future Research}

Imagine a CCL landscape of many dimensions to ultimately predict or anticipate the best levers or values to focus upon while mindful of other organisations in your industry sector. Such a landscape allows companies to see who is close to whom in terms of culture values and assess if their culture is drifting to a healthy/toxic industry standard. CCL (figure 3) can be applied to detect new or emerging culture changes in the industry to considering long term "what if ?" scenarios. CCL builds upon an open source embedding projector (Smikov et al., 2016) for visualisation of culture data. 


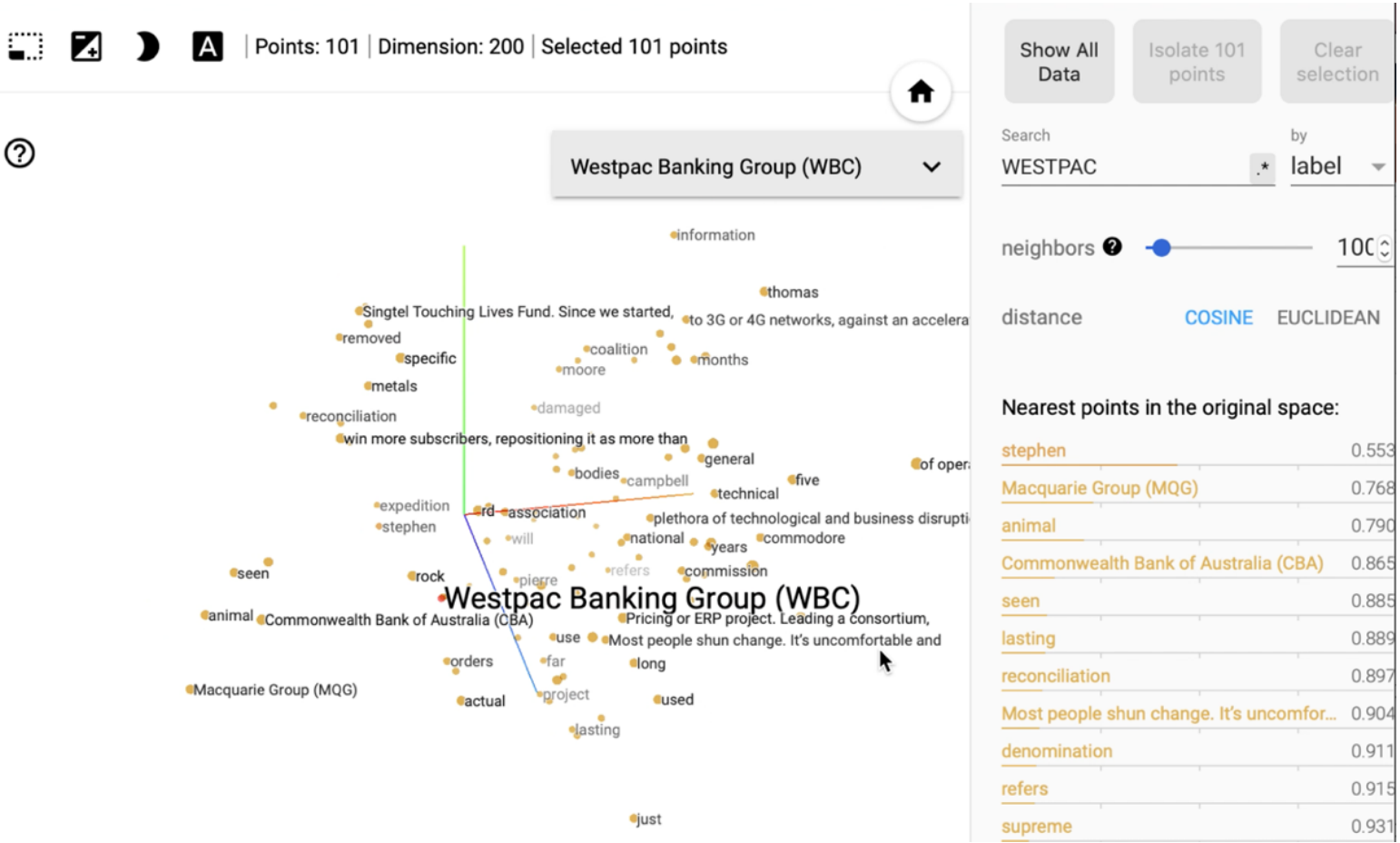

Figure 3: Company Culture Landscape Highlighting Major Australian Banks

This landscape helps visualise how different organisations position with regard to each other's culture. Overall the CCL generates from literally every key public source of company information including annual reports, websites, social media. Culture is described and enshrined within the vast amount of ever growing texts. Recognising up to twenty company values organisations have an ability to position on a landscape and plan moves value by value e.g. move from toxic to healthy culture or compare similar companies in the same industry by value and overall culture (see figure 4 for a comparison of cultures between Australian banks by values).

CCL is useful for a variety of executives not only company execs but regulators, academics and investment managers. The ability to illustrate the opportunity of actually being able to work with company cultures in a multidimensional space is a completely unique approach for HR professionals, company executives and managers. In the space the meaning of similar words and phrases are close to one another. Demonstrations of companies positioning within the CCL has been tested by the researchers for key Australian Stock Exchange Companies. Outputs are multidimensional and 2D for

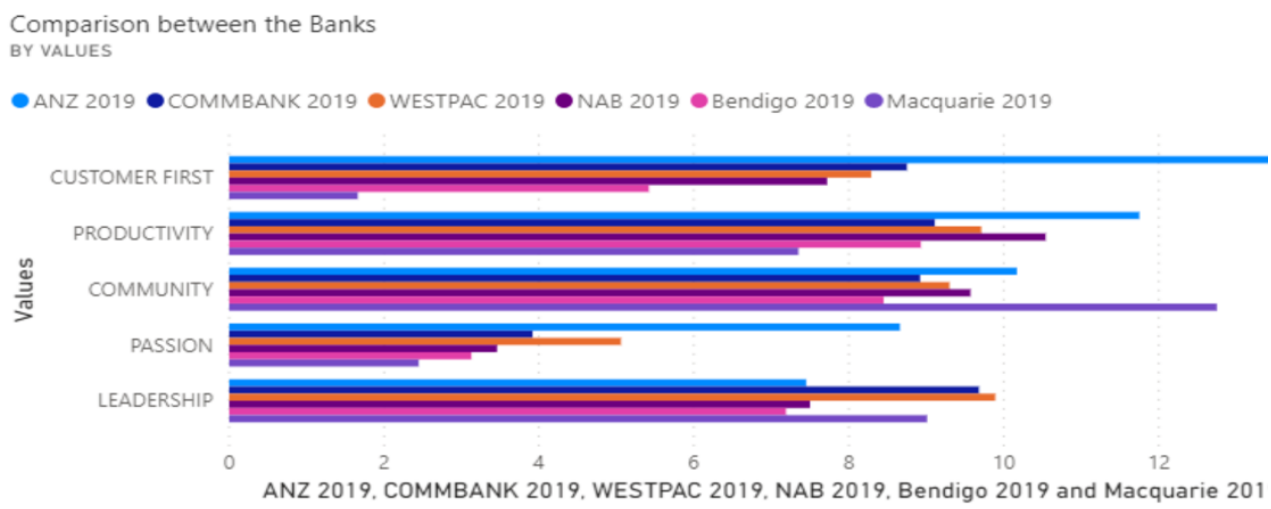

immediate action on culture dynamics by value.

Figure 4: Company Culture Landscape Highlighting Major Australian Banks 
The CCL highlights a big data approach to measuring culture and toxicity using observable communication data. This paper describes the methodology to measure culture commencing with a dictionary centric values approach to help verify and automate the extraction of culture and values from unstructured sources of information available to the business using a deep learning methodology and AI technology of neural networks.

\section{References}

- Abc.net.au, (2019) 'French telecom company Orange found guilty of 'moral harassment' resulting in workers' suicides' Abc.net.au viewed on 9 January $2020<\underline{\text { https://www.abc.net.au/news/2019-12-21/french-telco- }}$ orange-found-guilty-over-former-workers-suicides/11820172>

- Andrus J (2019) 'How I Did It: Traeger's CEO On Cleaning Up A Toxic Culture’ Harvard Business Review, March-April, pp33-37

- Appelbaum, SH, Roy-Girard, D (2007) 'Toxins in the workplace: affect on organizations and employees' Corporate Governance; Bradford Vol. 7, Iss.1 pp 17-28 CrossRef

- Arthur, M 2018 'Truth about Aussie cricket culture', Players Voice, viewed 3 May 2019 $<\underline{\text { https://www.playersvoice.com.au/mickey-arthur-truth-about-aussie-cricket- }}$ culture/\#kkDdDBTg3SBzIQp6.97>

- Bagshaw, E 2018, 'Damning' rap sheet: Scott Morrison expects CBA board members and executives to resign',

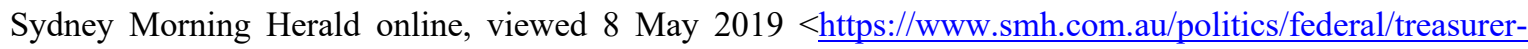
scott-morrison-tells-cba-board-members-to-resign-20180501-p4zckw.html>

- Bersin, J (2016) 'A New Market is Born: Employee Engagement, Feedback, and Culture Apps' JoshBersin.com, viewed on April 12, $2019<$ https://joshbersin.com/2015/09/a-new-market-is-born-employeeengagement-feedback-and-culture-apps/>

- Bilton, N 2019 ‘As Theranos Burned, Elizabeth Holmes was partying at - Burning Man’, Vanity Fair, viewed on 3 May $2019<\underline{\text { https://www.vanityfair.com/news/2019/02/as-theranos-burned-elizabeth-holmes-was- }}$ partyingat-burning-man $>$

- Bradley, L (2019) 'Former CBS Executive slams the network for its "white problem", Vanity Fair, viewed on 3 May $2019<$ https://www.vanityfair.com/hollywood/2019/04/cbs-diversity-problem-whitney-davisessay>

- Bremer, M (2019) 'Tough or Toxic Culture? You Pay' Leaderhip and Change Magazine, viewed on April 13, $2019<$ https://www.leadershipandchangemagazine.com/tough-or-toxic-culture-you-pay/>

- Caprar DV; Devinney TM; Kirkman BL, Caligiuri, P (2015) 'Conceptualizing and measuring culture in international business and management: From challenges to potential solutions', Journal of International Business Studies, suppl. Special Issue: What Is Culture and How Do We Measure It?; Basingstoke Vol. 46, Iss. 9 pp: 1011-1027. CrossRef

- Carreyrou, J (2018) Bad Blood: Secrets and Lies in a Silicon Valley Startup, Picador, US

- CEO.com (2019) 'How Traeger found its spark' Domo, viewed on August 3, 2019 $<$ https://www.domo.com/blog/how-traeger-found-its-spark/ >

- Chalmers, S, Worthington B (2019) 'Banking royal commission calls for compensation, crackdowns and an overhaul of financial regulators', ABC News online, viewed on 19 May 2019 $<$ https://www.abc.net.au/news/2019-02-04/banking-royal-commission-report-at-a-glance/10777188>

- Clausen, T, Borg, V (2011) "Job Demands, Job Resources and Meaning at Work' Journal of Managerial Psychology 26, no. 8, pp: 665-81 CrossRef

- Cooke, RA, and Rousseau DM (1988) 'Behavioral Norms and Expectations: A Quantitative Approach To the Assessment of Organizational Culture’ Group \& Organization Management 13, no. 3 pp 245-73. CrossRef

- Cricket culture: Damning report: Cricket Australia has been labelled "arrogant and controlling" in a scathing independent review. ABC News NSW (ABC1 Sydney), Monday, 29th October 2018;

- Detert, JR, Schroeder, RG, Mauriel, JJ (2000) 'A framework for linking culture and improvement initiatives in organizations' Academy of Management. The Academy of Management Review; Briarcliff Manor Vol. 25, Iss. 4, pp:850-863.

- Eaglebarger,S (2017) 'Engaging employees beyond the office freebies', Strategic HR Review, Vol. 16 Issue: 3, pp.112-116 CrossRef 
- Elzinga, D n.d. 'How the best organizations measure culture' CultureAmp.com viewed 12 April $2019<$ https://blog.cultureamp.com/blog/how-the-best-organizations-measure-culture $>$

- Farrow, R, (2018) 'Les Moonves and CBS Face Allegations of Sexual Misconduct', The New Yorker, viewed May 3, 2019, <https://www.newyorker.com/magazine/2018/08/06/les-moonves-and-cbs-face-allegations-ofsexual-misconduct>

- Feldman, A (2017) 'Jeremy Andrus Found Success With Skullcandy. Now He Hopes To Do It Again With Traeger Grills' Forbes, viewed May 3 201< https://www.forbes.com/sites/forbestreptalks/2017/10/22/jeremyandrus-found-success-with-skullcandy-now-he-hopes-to-do-it-again-with-traeger-grills/\#7b95cbcf17ea $>$ CrossRef

- Feldman M, Sko"ldberg K, Brown R, Horner, D (2004) 'Making Sense of Stories: A Rhetorical Approach to Narrative Analysis' Journal of Public Administration Research and Theory, Vol. 14, no. 2, pp. 147-170

- Garfield, D (2015) 'Inside Atlassian; building a culture of innovation' Atlassian.com, viewed 3 May, 2019

- <https://www.atlassian.com/blog/inside-atlassian/how-atlassian-builds-innovation-culture>

- Garton, E. and Mankins, M (2020) 'The Pandemic Is Widening a Corporate Productivity Gap', Harvard Business Review, December, https://hbr.org/2020/12/the-pandemic-is-widening-a-corporate-productivity-gap

- Gideon, H 2018, 'CA finally gets one over warner' The Australian, 30 March 2018, viewed 3 May 2019 $<$ https://www.theaustralian.com.au/nation/inquirer/steve-smith-david-warner-sent-home-but-who-willjudge-the-cricket-australia-suits/news-story/4b1dcce97ba702a6fef06f99c4eafe15>

- Glynn, MA, Giorgi, S, Lockwood, C (2013) 'Organisation Culture' Oxford Bibliographies in Management viewed April 20, $2019<$ <ttp://www.oxfordbibliographies.com/view/document/obo-9780199846740/obo9780199846740-0059.xml>

- Glynn, MA, Giorgi, S, Lockwood, C (2015) 'The Many Faces of Culture: Making Sense of 30 Years of Research on Culture in Organization Studies' The Academy of Management Annals, 9:1, pp1-54. CrossRef

- Gottshalk,M (2012) 'Can We Prevent Organizational Culture Failures?', MarlaGottschalk.com, viewed 29 April 2019,<https://marlagottschalk.com/2012/08/14/can-we-prevent-organizational-culture-failures-2/>

- Graham, J, Campbell H, Jillian P, and Shivaram R (2017) "Corporate Culture: Evidence from the Field." NBER Working Paper Series, Mar 2017, p.23255

- Gupta V (2011) 'Cultural basis of high performance organizations', International Journal of Commerce and Management, Vol. 21 Issue: 3, pp.221-240 CrossRef

- Haring, B (2018) '60 Minutes' Executives Created Toxic Workplace Culture, Law Firm Report Alleges', Deadline, viewed 3 May 2019, <https://deadline.com/2018/12/60-minutes-execs-created-toxic-workplaceculture-law-firm-report-alleges-1202515709/>

- Hayne, K (2019) Royal Commission into Misconduct in the Banking, Superannuation and Financial Services Industry:Final Report Commonwealth of Australia $<$ https://www.royalcommission.gov.au/sites/default/files/2019-02/fsrc-volume-1-final-report.pdf $>$

- Hillstrom, LC (2019), 'The \#MeToo Movement' ABC-CLIO, California pp.69-71

- Ibrahim, M, Torki, M, El-Makky, N (2018) 'Imbalanced toxic comments classification using data augmentation and deep learning', ResearchGate, https://www.researchgate.net/publication/329152015 CrossRef

- Kaggle (2018) Toxic Comment Classification Challenge - Identify and classify toxic online comments https://www.kaggle.com/c/iigsaw-toxic-comment-classification-challenge

- Kazoo (2020), Employee Experience Cheat Sheet, viewed 12 January $2020<$ https://info.kazoohr.com/resource-guide-employee-experience-cheat-sheet>

- Klein, L (2008) The Meaning of Work Papers on Work Organization and the Design of Jobs. Karnac, London.

- Leung, K, Morris, M (2015) 'Values, Schemas, and Norms in the Culture-behavior Nexus: A Situated Dynamics Framework' Journal of International Business Studies 46, no. 9. CrossRef

- Lloyd, A (2018), 'What Defines Employee Engagement?. Recognition and Engagement' Excellence Essentials; Aurora; May 2018

- Lysova, E, Allan, B, Dik, B, Duffy, R, Steger, M (2019) 'Fostering meaningful work in organizations: A multilevel review and integration' Journal of Vocational Behavior Volume 110, Part B, pp 374-389

- Mohr, JW, Ghazianni, A 2014 'Problems and prospects of measurement in the study of culture' Theory and Society; Dordrecht Vol. 43, Iss. 3-4 CrossRef 
- Morgan, J 2014, The Future of Work: Attract New Talent, Build Better Leaders, and Create a Competitive Organisation, John Wiley \& Sons Inc, US

- Murphy K, 2018 'Banking royal commission condemns greed of financial sector in first report' The Guardian Online, viewed 8 May, $2019<\underline{\text { https://www.theguardian.com/australia-news/2018/sep/28/banking-royal- }}$ commission-condemns-greed-of-financial-sector-in-first-report>

- National Australia Bank 2018, 'NAB releases self-assessment into governance, accountability and culture', NAB Media release 30 November 2018.

- Nossiter, A 2019 ‘35 Employees Committed Suicide. Will Their Bosses Go to Jail?’ The New Yorker, viewed 9 January 2020 < https://www.nytimes.com/2019/07/09/world/europe/france-telecom-trial.html?>

- Rasca, L 2018 'Employee experience - An answer to the deficit of talents, in the fourth industrial revolution' Quality - Access to Success, 1 October 2018, Vol.19(3), pp.9-14

- Ryan W. Tang, 2017 'Watch his deed or examine his words? Exploring the potential of the behavioral experiment method for collecting data to measure culture', Cross Cultural \& Strategic, Management, Vol. 24 Issue: 4, pp.669-695 CrossRef

- Shah, D, 2018.'The HubSpot Culture Code: Creating a Company We Love' Hubspot, viewed 3 May 2019 $<\underline{\text { https://blog.hubspot.com/blog/tabid/6307/bid/34234/the-hubspot-culture-code-creating-a-company-we- }}$ $\underline{\text { love.aspx }>}$

- Smilkov, D and Big Picture group (2016), Open sourcing the Embedding Projector: a tool for visualizing high dimensional data, https://opensource.googleblog.com/2016/12/open-sourcing-embedding-projector-tool.html

- Smith, E 2013, 'Social Connection Makes a Better Brain', The Atlantic, viewed April 20 $<$ https://www.theatlantic.com/health/archive/2013/10/social-connection-makes-a-better-brain/280934/>

- Srivastava, SB, Goldberg, A 2017 'Language as a window into culture', California Management Review, November 2017, Vol.60(1), pp.56-69 CrossRef

- Thebault R, 2019 'Three French executives convicted in the suicides of 35 of their workers' SMH.com.au, viewed 9 January 2020.

- The Ethics Centre, A matter of balance, A report commissioned by the board of Cricket Australia, 28 October 2018, Cricket Australia viewed on April 12, $2019<\underline{\text { https://www.cricketaustralia.com.au/- }}$ /media/B9F2F708C1A540A08847A4758D02CB99.ashx >.

- The Slack Team, 2015, 'Building the workplace we want' SlackHQ.com viewed 3 May 2019, $<$ https://slackhq.com/building-the-workplace-we-want $>$

- Vantrappen, H, de Jong, R 2018 'How to write a company value statement that will achieve strategic impact' Strategy \& Leadership, 2018, Vol.46(2), pp.41-47

- Venaik, S, Midgley, DF 2015 'Mindscapes across Landscapes: Archetypes of Transnational and Subnational

- Waters, Sarah. 2014 "A Capitalism That Kills: Workplace Suicides at France Telecom." French Politics, Culture and Society 32.3 (2014): 121-141. Web. CrossRef

- Webber, T 2018 Ball-tampering scandal: Former coach Mickey Arthur slams Australia team culture https://www.sportingnews.com/au/cricket/news/australia-ball-tampering-mickev-arthur-davidwarner/3101m9ziin081 reiw1fddg73i

- Wickham, N 2017 'The Consumerization of HR: What Does It Mean for the Performance Management Process?' 23 April, https://www.quantumworkplace.com/future-of-work/the-consumerization-of-hr-whatdoes-it-mean-for-the-performance-management-process.

- Woodside, AG, Sood, SC 2016 'Storytelling-Case Archetype Decoding and Assignment Manual (SCADAM)', Storytelling-Case Archetype Decoding and Assignment Manual (SCADAM), Iii. Vol. 11, Emerald Group Publishing Limited, 2016. CrossRef

- Ying, J 2015 'Case study: Lessons learned from Theranos' corporate culture' Medium.com, viewed on April $232019<\underline{\text { https://medium.com/the-coleman-fung-institute/case-study-lessons-learned-from-theranos- }}$ corporate-culture-1a836515c139> 